\title{
Hemipelvectomy Type I
}

National Cancer Institute

\section{Source}

National Cancer Institute. Hemipelvectomy Type I. NCI Thesaurus. Code C157648.

A hemipelvectomy with the resection confined to ilium. 